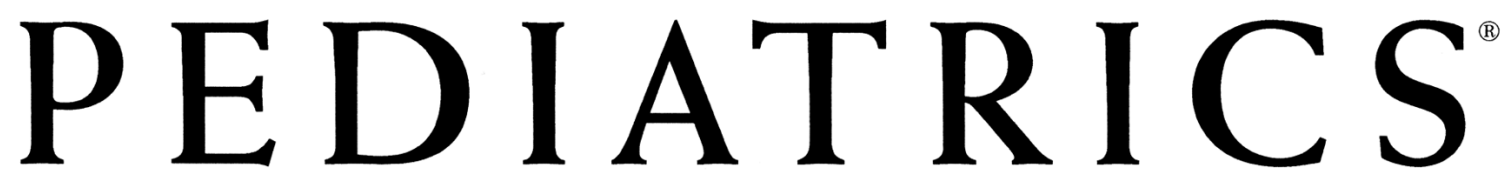

OFFICIAL JOURNAL OF THE AMERICAN ACADEMY OF PEDIATRICS

\title{
Factors Associated With Establishing a Causal Diagnosis for Children With
} Cardiomyopathy

Gerald F. Cox, Lynn A. Sleeper, April M. Lowe, Jeffrey A. Towbin, Steven D. Colan,

E. John Orav, Paul R. Lurie, Jane E. Messere, James D. Wilkinson and Steven E. Lipshultz

Pediatrics 2006;118;1519-1531

DOI: $10.1542 /$ peds.2006-0163

\section{This information is current as of October 4, 2006}

The online version of this article, along with updated information and services, is located on the World Wide Web at:

http://www.pediatrics.org/cgi/content/full/118/4/1519

PEDIATRICS is the official journal of the American Academy of Pediatrics. A monthly publication, it has been published continuously since 1948. PEDIATRICS is owned, published, and trademarked by the American Academy of Pediatrics, 141 Northwest Point Boulevard, Elk Grove Village, Illinois, 60007. Copyright ( 2006 by the American Academy of Pediatrics. All rights reserved. Print ISSN: 0031-4005. Online ISSN: 1098-4275.

\section{American Academy of Pediatrics}




\title{
Factors Associated With Establishing a Causal Diagnosis for Children With Cardiomyopathy
}

\author{
Gerald F. Cox, MD, PhDa,b,c, Lynn A. Sleeper, ScDd, April M. Lowe, MSd, Jeffrey A. Towbin, MDe, Steven D. Colan, MD b,f, E. John Orav, PhDg,h, \\ Paul R. Lurie, MDi, Jane E. Messere, RN' ${ }^{f}$ James D. Wilkinson, MD, MPH', Steven E. Lipshultz, MDj \\ aDivision of Genetics, Department of Medicine, and fDepartment of Cardiology, Children's Hospital, Boston, Massachusetts; Departments of bPediatrics and 9|nternal \\ Medicine, Harvard Medical School, Boston, Massachusetts; ' Clinical Research, Genzyme Corp, Cambridge, Massachusetts; dNew England Research Institutes, Watertown, \\ Massachusetts; eDepartments of Pediatric Cardiology, Molecular and Human Genetics, and Cardiovascular Sciences, Texas Children's Hospital and Baylor College of

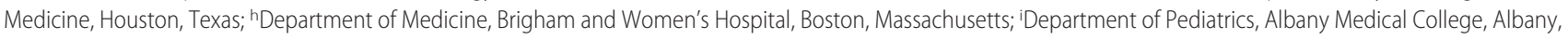 \\ New York; 'Department of Pediatrics, University of Miami Leonard M. Miller School of Medicine, Holtz Children's Hospital of the University of Miami-Jackson Memorial \\ Medical Center, Batchelor Children's Research Institute and Mailman Institute for Child Development, Miami, Florida
}

Financial Disclosure: Dr Cox is an employee of Genzyme Corp, which develops and markets drugs used to treat lysosomal storage disorders, some of which may manifest cardiomyopathy. Genzyme had no involvement in this study.

\section{ABSTRACT}

OBJECTIVE. The goal was to identify the clinical variables associated with establishing a cause of cardiomyopathy in children.

METHODS. The Pediatric Cardiomyopathy Registry contains clinical and causal testing information for 916 children who were diagnosed as having cardiomyopathy in North America between 1990 and 1995. Children with a causal diagnosis were compared with those without with respect to several demographic, clinical, and causal testing variables.

RESULTS. Cardiomyopathy was 1 of 4 types, hypertrophic (34.2\%), dilated (53.8\%), restrictive $(3.2 \%)$, or other or mixed $(8.9 \%)$. Only one third of cases had a known cause. Children with a known cause for hypertrophic cardiomyopathy were more likely to be female, to be relatively smaller, to present with congestive heart failure, and to have increased left ventricular posterior wall thickness without outflow tract obstruction. For dilated cardiomyopathy, a known cause was associated with older age, lower heart rate, smaller left ventricular dimensions, and greater shortening fraction. Family history of cardiomyopathy predicted a significantly higher rate of causal diagnoses for all cardiomyopathy types, whereas family histories of genetic syndromes and sudden death were also predictive of a cause for hypertrophic and dilated cardiomyopathies. For hypertrophic cardiomyopathy, only blood and urine testing was associated with a causal diagnosis, whereas both viral serologic testing or culture and endomyocardial biopsy were independent predictors of a causal diagnosis in dilated cardiomyopathy.

CONCLUSIONS. Certain patient characteristics, family history, echocardiographic findings, laboratory testing, and biopsy were associated significantly with establishing a cause of pediatric cardiomyopathy. Early endomyocardial biopsy should be considered strongly for children with dilated cardiomyopathy, for definitive diagnosis of viral myocarditis. Although not widely used, skeletal muscle biopsy may yield a cause for some patients with hypertrophic cardiomyopathy and for patients suspected of having a mitochondrial disorder.

www.pediatrics.org/cgi/doi/10.1542/ peds.2006-0163

doi:10.1542/peds.2006-0163

Key Words

idiopathic cardiomyopathy, hypertrophic cardiomyopathy, dilated cardiomyopathy, restrictive cardiomyopathy, myocarditis, inborn errors of metabolism, malformation syndrome, neuromuscular, endomyocardial biopsy

Abbreviations

PCMR - Pediatric Cardiomyopathy Registry HCM - hypertrophic cardiomyopathy DCM - dilated cardiomyopathy RCM-restrictive cardiomyopathy CHF_-congestive heart failure

Accepted for publication May 23, 2006

Address correspondence to Steven E. Lipshultz, MD, Department of Pediatrics (D820), University of Miami Leonard M. Miller School of Medicine, PO Box 016820, Miami, FL 33101. E-mail: slipshultz@med.miami.edu PEDIATRICS (ISSN Numbers: Print, 0031-4005; Online, 1098-4275). Copyright $\odot 2006$ by the American Academy of Pediatrics 
$\mathrm{P}$ EDiatric CaRdiomyopathy is a rare but serious and often life-threatening condition. Two recent epidemiologic studies in the United States and Australia have estimated the incidence to be 1.1 to 1.2 cases per 100000 children, with rates that are 8 to 12 times higher in infants than in older children. ${ }^{1,2}$ Nearly $40 \%$ of children with symptomatic cardiomyopathy receive a transplant or die within 2 years, and outcomes have not improved substantially, despite advances in medical care and technology. ${ }^{3}$ In children, cardiomyopathy is often part of a multisystem disorder that requires the attention of multiple subspecialists. The cause of cardiomyopathy is unknown, or idiopathic, for $57 \%$ to $68 \%$ of children, which likely contributes to poor outcomes. ${ }^{1,2}$

The low causal diagnostic rate is likely the result of several factors, including the large number of genetic and acquired causes of cardiomyopathy; diagnostic tests that are available in only a few specialized centers (eg, metabolic tests) or that are slow to be translated from research to clinical laboratories (eg, genetic tests); and the lack of a systematic approach to diagnosis. ${ }^{4-6}$ Guidelines for evaluation ${ }^{7}$ and diagnostic algorithms ${ }^{4}$ based on clinical presentation have been developed, but their implementation and usefulness have not been tested prospectively in clinical practice. The few studies that have screened systematically for causes of cardiomyopathy in selected groups of children have identified a variety of metabolic, mitochondrial, and viral causes in substantial proportions of patients. ${ }^{8}$ Importantly, the condition of children with cardiomyopathy has improved after treatment based on the underlying cause. ${ }^{9-15}$

In 1994, the Pediatric Cardiomyopathy Registry (PCMR) was funded by the National Heart, Lung, and Blood Institute, to study the epidemiologic features and clinical course of pediatric cardiomyopathy in the United States and selected regions. ${ }^{16}$ The PCMR consists of 2 data sets. One is a retrospectively collected data set of detailed information on children diagnosed between 1990 and 1995, which permits study of the causes and natural history of cardiomyopathy. The other is a prospective data set of children diagnosed since 1996, which includes as a major subset the complete capture of new cases in 2 regions of the United States and permits study of the incidence and epidemiologic features of cardiomyopathy.

In this report, we analyzed data for the 916 children in the retrospective data set of the PCMR, to characterize the various causes of cardiomyopathy and to identify variables that are associated with establishing a cause. We asked whether the rates of cardiomyopathy with and without known causes differed as a function of patient, disease, or clinical practice variables. Such variables, if identified, might lead to better diagnostic and treatment strategies.

\section{METHODS}

\section{Study Design}

The design of the PCMR has been described in detail elsewhere. ${ }^{16}$ This report is based on the retrospective data set of the PCMR, which includes detailed diagnostic and management data on 916 children with cardiomyopathy who presented to a pediatric cardiologist between January 1, 1990, and December 31, 1995, at 1 of 38 sites in the United States (814 patients) or Canada (102 patients). Two patients were excluded from analyses, 1 with missing cause status and 1 with a known cause of unspecified type. The window for baseline registry data was the 1-month period after the initial diagnosis of cardiomyopathy.

The protocol was reviewed and approved by the institutional review boards or ethics committees at all participating PCMR sites. Written informed consent from individual patients or surrogates was not required, because there was no direct patient contact and no procurement of medical materials other than written records.

\section{Eligibility Criteria}

To be eligible for the PCMR, a patient was required to be $<18$ years of age at diagnosis and to meet specific echocardiographic, pathologic, or clinical criteria for cardiomyopathy. ${ }^{16}$ Of the 14 clinical exclusion criteria, ${ }^{16}$ the most common were congenital heart defect not associated with a malformation syndrome, endocrine disease known to cause myocardial damage, chronic arrhythmia, pulmonary parenchymal or vascular disease, immunologic disease, and drug use known to cause hypertrophy.

\section{Definitions of Cardiomyopathy}

Cardiomyopathy was classified as pure if it consisted of 1 functional type only (dilated cardiomyopathy [DCM], hypertrophic cardiomyopathy [HCM], or restrictive cardiomyopathy [RCM]) or mixed if it had features of $>1$ functional type. Although the World Health Organization classifies acute viral myocarditis as an inflammatory cardiomyopathy distinct from DCM, ${ }^{17}$ both groups were classified here as DCM because of their similar echocardiographic appearances. Similarly, in the adult cardiomyopathy literature, HCM denotes a sarcomeric defect as the specific cause. ${ }^{18}$ Here, we combined all cases that shared a hypertrophic functional type, as indicated by echocardiography, irrespective of cause.

Cardiomyopathy was defined as familial when it occurred in $\geq 2$ family members, irrespective of functional type, cause, or inheritance pattern. Familial isolated cardiomyopathy was defined as cardiomyopathy with no systemic features occurring in $\geq 2$ family members, a single proband with an identified genetic defect, or a metabolic disorder known to cause isolated cardiomyop- 
athy. The cause of familial isolated cardiomyopathy was considered to be known when a specific inheritance pattern could be inferred or when the genetic defect was identified and to be unknown when the relationship to affected relatives (eg, non-first-degree relatives) precluded assignment of a conventional inheritance pattern (autosomal recessive, autosomal dominant, $\mathrm{X}$-linked, or mitochondrial). When $>1$ inheritance pattern was theoretically possible, the more-conventional pattern was assumed. For example, if a brother and sister were affected and both parents had negative echocardiograms, then the inheritance pattern was described as autosomal recessive, although autosomal dominant with incomplete penetrance would be possible.

Specific laboratory testing included viral serologic testing or culture, chromosomal analysis, metabolic testing, and biopsy. Testing was performed at the discretion of the participating center. Metabolic blood testing was defined as having measurements for $\geq 1$ of the following: ammonia, creatine phosphokinase, carnitine, free fatty acids, lactate, pyruvate, quantitative ketones, acylcarnitines, or amino acids. Metabolic urine testing was defined as having measurements for $\geq 1$ of the following: acylglycines, quantitative amino acids, mucopolysaccharides or oligosaccharides, organic acids, or ketones. Biopsy referred to endomyocardial or skeletal muscle biopsy procedures.

\section{Statistical Methods}

Fisher's exact test was used to compare the rates of known versus unknown causes in patient subgroups defined by categorical variables, unless otherwise noted. The distributions of continuous variables according to causal status were compared with Student's $t$ test or Wilcoxon's rank-sum test, as appropriate. Multivariate logistic regression was used to determine which diagnostic tests were independent predictors of a known cause, adjusted for 3 potential confounders (age, presence or absence of congestive heart failure $[\mathrm{CHF}]$ at cardiomyopathy diagnosis, and geographic region). The significance level was set at .05, and all tests were 2-tailed. All analyses were conducted with SAS version 8.2 (SAS Institute, Cary, NC) and S-Plus version 6.1 (Insightful Corp, Seattle, WA) software.

Blood and urine tests and biopsies were analyzed statistically in 2 stages, that is, initially for all patients with a definitive testing status and then after certain subgroups of patients, whose diagnoses generally were established through other means, were excluded. For the latter analyses, patients with neuromuscular disease $(n=68)$ were excluded, because typically musculoskeletal disease is identified before cardiomyopathy develops and test results obtained before cardiomyopathy was diagnosed were not collected in the PCMR. Patients with familial isolated cardiomyopathy $(n=74)$ or a malformation syndrome $(n=27)$ also were excluded, because typically these diagnoses are made through echocardiographic evaluation of other family members and physical examination, respectively.

\section{RESULTS}

\section{Sample Characteristics}

The patient sample was $58.2 \%$ male, $66.9 \%$ white, $17.0 \%$ black, $11.3 \%$ Hispanic, and $4.9 \%$ other race or ethnicity. The median age at diagnosis was 2.3 years (interquartile range, $0.4-11.3$ years). Family histories of cardiomyopathy, sudden death, or genetic syndrome were present in $23.7 \%, 11.6 \%$, and $6.1 \%$ of cases, respectively. Patients were classified as having been diagnosed in Canada (11.1\%) or in 1 of 7 geographic regions of the United States $(88.9 \%)$, with the largest contributors in the Southwest $(29.0 \%$ of US patients; Arizona, New Mexico, Nevada, Oklahoma, and Texas), Northeast (20.2\%; Connecticut, Massachusetts, Maine, New Hampshire, Vermont, and Rhode Island), and Atlantic (17.1\%; District of Columbia, Maryland, New Jersey, New York, and Pennsylvania) regions. More than one half $(53.8 \%)$ of the children were diagnosed as having DCM, one third (34.2\%) HCM, 3.2\% RCM, and $8.9 \%$ other or mixed type of cardiomyopathy.

Only one third $(33.3 \%$, or 305$)$ of the 916 patients with cardiomyopathy had a known cause at diagnosis (Table 1). The known causes for the 112 patients with HCM were nearly evenly distributed among familial isolated cardiomyopathy, inborn errors of metabolism (most commonly Pompe disease), neuromuscular disorders (most commonly Friedreich's ataxia), and malformation syndromes (most commonly Noonan syndrome). In contrast, myocarditis $(51.6 \%)$ was among the most common known causes for the 161 patients with pure DCM, followed by neuromuscular disorders (25.5\%; most commonly Duchenne muscular dystrophy) and familial isolated cardiomyopathy (15.5\%). All 6 of the 29 RCM cases with known cause were familial isolated RCM. Approximately one half $(46.2 \%)$ of the 26 known causes in the mixed or other cardiomyopathy group (81 patients) were familial isolated cardiomyopathy, and one fourth each were myocarditis $(23.1 \%)$ and inborn errors of metabolism $(26.9 \%)$.

\section{Associations Between Causal Status and Patient Characteristics}

For patients with HCM, gender was associated with having a known cause, but age at diagnosis of cardiomyopathy was not (Table 2). Girls were more likely to have a known cause than were boys $(48.2 \%$ vs $29.3 \%$; $P=$ $.001)$. Among those with known causes, a disproportionate number of the girls $(36.5 \%)$ had familial isolated HCM, compared with the boys $(20.0 \%)$. Patients with 
TABLE 1 Specific Causes of Cardiomyopathy According to Type for 305 Children From the PCMR Retrospective Cohort

\begin{tabular}{|c|c|c|c|c|c|c|c|c|c|c|}
\hline \multirow[t]{2}{*}{ Cause of Cardiomyopathy } & \multicolumn{2}{|c|}{$\begin{array}{l}\text { All Known } \\
\text { Causes } \\
(n=305)\end{array}$} & \multicolumn{2}{|c|}{$\mathrm{HCM}(n=112)$} & \multicolumn{2}{|c|}{$\operatorname{DCM}(n=161)$} & \multicolumn{2}{|c|}{$\mathrm{RCM}(n=6)$} & \multicolumn{2}{|c|}{$\begin{array}{c}\text { Other or Mixed } \\
\text { Cardiomyopathy } \\
(n=26)\end{array}$} \\
\hline & No. & $\%$ & No. & $\%$ & No. & $\%$ & No. & $\%$ & No. & $\%$ \\
\hline Myocarditisa & 89 & 29.2 & 0 & 0.0 & 83 & 51.6 & 0 & 0.0 & 6 & 23.1 \\
\hline Confirmed with Dallas criteria on biopsy & 52 & 58.4 & & & 49 & 59.0 & & & 3 & 50.0 \\
\hline Probable & 37 & 41.6 & & & 34 & 41.0 & & & 3 & 50.0 \\
\hline Familial isolated cardiomyopathya & 74 & 24.3 & 31 & 27.7 & 25 & 15.5 & 6 & 100 & 12 & 46.2 \\
\hline Autosomal dominant & 51 & 68.9 & 27 & 87.1 & 16 & 64.0 & 2 & 33.3 & 6 & 50.0 \\
\hline X-linked & 3 & 4.1 & 0 & & 1 & 4.0 & 0 & & 2 & 16.7 \\
\hline Autosomal recessive $^{b}$ & 20 & 27.0 & 4 & 12.9 & 8 & 32.0 & 4 & 67.7 & 4 & 33.3 \\
\hline Neuromuscular disordera & 68 & 22.3 & 26 & 23.2 & 41 & 25.5 & 0 & 0.0 & 1 & 3.8 \\
\hline Muscular dystrophies & 43 & 63.2 & 2 & 7.7 & 40 & 97.6 & & & 1 & 100 \\
\hline Ataxias & 25 & 36.8 & 24 & 92.3 & 1 & 2.4 & & & 0 & \\
\hline Inborn errors of metabolisma & 47 & 15.4 & 30 & 26.8 & 10 & 6.2 & 0 & 0.0 & 7 & 26.9 \\
\hline Disorder of glycogen metabolism & 14 & 29.8 & 13 & 43.3 & 0 & & & & 1 & 14.3 \\
\hline $\begin{array}{l}\text { Disorder of mucopolysaccharide or } \\
\text { oligosaccharide degradation }\end{array}$ & 3 & 6.4 & 2 & 6.7 & 1 & 10.0 & & & 0 & \\
\hline Disorder of pyruvate metabolism & 1 & 2.1 & 1 & 3.3 & 0 & & & & 0 & \\
\hline Disorder of oxidative phosphorylation & 16 & 34.0 & 7 & 23.3 & 4 & 40.0 & & & 5 & 71.4 \\
\hline Disorder of fatty acid metabolism & 12 & 25.5 & 7 & 23.3 & 4 & 40.0 & & & 1 & 14.3 \\
\hline $\begin{array}{l}\text { Disorder of amino acid or organic acid } \\
\text { metabolism }\end{array}$ & 1 & 2.1 & 0 & & 1 & 10.0 & & & 0 & \\
\hline Malformation syndrome ${ }^{a}$ & 27 & 8.9 & 25 & 22.3 & 2 & 1.2 & 0 & 0.0 & 0 & 0.0 \\
\hline Autosomal dominant & 24 & 88.9 & 24 & 96.0 & 0 & & & & & \\
\hline Autosomal recessive & 1 & 3.7 & 1 & 4.0 & 0 & & & & & \\
\hline Chromosomal abnormality & 1 & 3.7 & 0 & & 1 & 50.0 & & & & \\
\hline Unknown genesis syndrome not specified & 1 & 3.7 & 0 & & 1 & 50.0 & & & & \\
\hline
\end{tabular}

Percentages are based on the cause-specific column sample size except where otherwise noted.

a Percentages based on sample size in column heading.

b This category may include cardiomyopathy that is autosomal dominant with reduced penetrance.

HCM who had a known cause were also smaller than those without a known cause, as evidenced by their lower mean height-for-age $z$ score $(-0.98$ vs $-0.34 ; P=$ $.02)$ and lower mean weight-for-age $z$ score $(-0.78$ vs $0.03 ; P<.001)$. The HCM subgroup with growth $z$ scores below the sample average consisted mainly of children with mitochondrial and other metabolic disorders, Noonan syndrome, or Friedreich's ataxia.

For patients with DCM, there were no gender differences according to causal status, but patients with a known cause were significantly older at the time of cardiomyopathy diagnosis than were those with an unknown cause (median age: 5.3 years vs 1.3 years; $P<$ $.001)$, largely as a result of patients with Duchenne and Becker muscular dystrophy (median age at diagnoses: 14.7 years and 14.2 years, respectively).

For patients with HCM and DCM, the rates of a known cause were significantly higher for patients with family histories of sudden death and genetic syndromes than for those without. For all 4 functional type groups, a family history of cardiomyopathy yielded a significantly higher rate of known causes, compared with that without such a family history, but causal status was not associated with year of diagnosis, medical insurance or type of insurance, or family history of congenital heart disease or arrhythmia.

\section{Associations Between Causal Status and Disease Characteristics}

There was no significant difference in the rates of known cause according to functional type (HCM, 35.8\%; DCM, $32.7 \%$; other or mixed cardiomyopathy, $32.1 \%$; RCM, $20.7 \%)$. Approximately one half $(51.0 \%)$ of all patients had CHF at the time of diagnosis. Only for the HCM group was the rate of known cause associated significantly with the presence of CHF at diagnosis $(51.9 \%$ for patients with CHF vs $32.6 \%$ for patients without CHF; $P$ $=.01)$. The most common cause among patients with HCM with CHF at the diagnosis of cardiomyopathy was inborn errors of metabolism $(59.3 \% ; 16$ of 27 patients).

Nearly all children underwent echocardiography $(95.6 \%)$ and electrocardiography $(80.3 \%)$, and smaller numbers underwent cardiac catheterization (32.2\%) and Holter monitoring $(21.9 \%)$ when presenting with cardiomyopathy. Although none of these cardiac assessments except Holter monitoring was associated significantly with a cause of cardiomyopathy, certain measurements were (Tables 3 and 4). Patients with HCM and a known cause had a higher mean end diastolic posterior wall thickness $z$ score (3.26 vs 2.04; $P=.008$ ) than did those with an unknown cause. This group included predominantly patients with a variety of mitochondrial and other metabolic disorders (especially Pompe disease) and 
TABLE 2 Rates of Known Causes of Cardiomyopathy Among 916 Children From the PCMR Retrospective Cohort, According to Demographic and Clinical Characteristics, Classified According to Type

\begin{tabular}{|c|c|c|c|c|c|c|c|c|c|c|}
\hline \multirow[t]{2}{*}{ Characteristic } & \multicolumn{2}{|c|}{ All $(n=916)$} & \multicolumn{2}{|c|}{$\operatorname{HCM}(n=313)$} & \multicolumn{2}{|c|}{$\operatorname{DCM}(n=492)$} & \multicolumn{2}{|c|}{$\operatorname{RCM}(n=29)$} & \multicolumn{2}{|c|}{$\begin{array}{c}\text { Other or Mixed } \\
\text { Cardiomyopathy }(n=81)\end{array}$} \\
\hline & \% Known Causes & $P$ & $\%$ Known Causes & $P$ & $\%$ Known Causes & $P$ & $\%$ Known Causes & $P$ & $\%$ Known Causes & $P$ \\
\hline Gender & & 1.00 & & .001 & & .21 & & .36 & & .09 \\
\hline Male & 33.2 & & 29.3 & & 35.2 & & 30.8 & & 40.4 & \\
\hline Female & 33.4 & & 48.2 & & 29.8 & & 12.5 & & 20.6 & \\
\hline $\begin{array}{l}\text { Age at diagnosis, } \\
\text { median } \\
\text { (interquartile } \\
\text { range), y }\end{array}$ & $\begin{array}{c}\text { Known: } 5.1 \\
(0.6-12.3) \\
\text { unknown: } 2.1 \\
(0.3-10.8)\end{array}$ & .003 & $\begin{array}{c}\text { Known: } 3.7 \\
(0.3-10.0) \\
\text { unknown: } 3.8 \\
(0.2-12.3)\end{array}$ & .78 & $\begin{array}{c}\text { Known: } 5.3 \\
(1.1-13.3) ; \\
\text { unknown: } 1.3 \\
(0.3-9.4)\end{array}$ & $<.001$ & $\begin{array}{c}\text { Known: } 3.9 \\
(2.4-6.8) ; \\
\text { unknown: } 4.6 \\
(2.3-8.3)\end{array}$ & .85 & $\begin{array}{c}\text { Known: } 3.0 \\
(0.5-14.0) \\
\text { unknown: } 4.2 \\
(0.6-12.0)\end{array}$ & .94 \\
\hline Age at diagnosis & & .08 & & .72 & & .01 & & 1.00 & & .33 \\
\hline$<2 y$ & 30.4 & & 34.5 & & 27.4 & & 16.7 & & 39.4 & \\
\hline$\geq 2 y$ & 35.9 & & 36.9 & & 38.3 & & 21.7 & & 27.1 & \\
\hline Race & & .04 & & .22 & & .24 & & .64 & & .49 \\
\hline White & 35.5 & & 37.8 & & 35.5 & & 30.0 & & 28.3 & \\
\hline Black & 23.5 & & 20.0 & & 24.8 & & 0.0 & & 27.3 & \\
\hline Hispanic & 33.3 & & 34.4 & & 32.1 & & 0.0 & & 45.5 & \\
\hline Other & 34.1 & & 33.3 & & 34.6 & & 0.0 & & 50.0 & \\
\hline Geographic region of diagnosis & & $.003^{\mathrm{a}}$ & & $.29^{\mathrm{a}}$ & & $.11^{\mathrm{a}}$ & & & & $.45^{\mathrm{a}}$ \\
\hline Atlantic & 23.7 & & 26.0 & & 24.4 & & 0.0 & & 25.0 & \\
\hline West & 25.0 & & 22.2 & & 27.3 & & 0.0 & & 33.3 & \\
\hline West Coast & 28.6 & & 39.1 & & 25.0 & & 0.0 & & 0.0 & \\
\hline Midwest & 27.1 & & 44.4 & & 28.6 & & 0.0 & & 0.0 & \\
\hline South & 30.0 & & 40.9 & & 30.5 & & 0.0 & & 0.0 & \\
\hline Southwest & 33.9 & & 33.3 & & 33.3 & & 28.6 & & 42.1 & \\
\hline Canada & 41.2 & & 38.8 & & 41.9 & & & & 50.0 & \\
\hline Northeast & 44.5 & & 46.6 & & 46.4 & & 66.7 & & 32.3 & \\
\hline Medical insurance & & .51 & & .49 & & .86 & & .38 & & .71 \\
\hline Yes & 34.0 & & 37.2 & & 33.0 & & 18.5 & & 34.3 & \\
\hline No & 29.6 & & 28.6 & & 30.8 & & 50.0 & & 22.2 & \\
\hline Type of insurance & & .41 & & 69 & & .26 & & .51 & & 1.00 \\
\hline Medicaid & 31.2 & & 36.8 & & 29.0 & & 0.0 & & 40.0 & \\
\hline Other & 35.6 & & 33.3 & & 37.6 & & 30.0 & & 39.1 & \\
\hline Year of diagnosis & & $.78^{\mathrm{b}}$ & & $.76^{\mathrm{b}}$ & & $.54^{b}$ & & $.09^{b}$ & & $.72^{\mathrm{b}}$ \\
\hline 1990 & 28.3 & & 24.4 & & 32.1 & & 0.0 & & 25.0 & \\
\hline 1991 & 35.9 & & 47.4 & & 29.9 & & 0.0 & & 44.4 & \\
\hline 1992 & 36.6 & & 40.0 & & 35.1 & & 0.0 & & 38.1 & \\
\hline 1993 & 31.0 & & 36.8 & & 29.2 & & 0.0 & & 29.4 & \\
\hline 1994 & 34.6 & & 40.0 & & 33.3 & & 50.0 & & 15.4 & \\
\hline 1995 & 33.0 & & 28.4 & & 35.7 & & 28.6 & & 38.5 & \\
\hline Family history of cardiomyopathy & & $<.001$ & & $<.001$ & & $<.001$ & & $<0.001$ & & $<.001$ \\
\hline Present & 60.8 & & 60.9 & & 52.5 & & 100 & & 76.2 & \\
\hline Absent & 24.8 & & 26.1 & & 26.7 & & 0.0 & & 15.8 & \\
\hline Family history of sudden death & & $<.001$ & & .004 & & $<.001$ & & & & .09 \\
\hline Present & 61.0 & & 60.0 & & 62.5 & & & & 58.3 & \\
\hline Absent & 28.8 & & 31.5 & & 28.0 & & 9.5 & & 29.8 & \\
\hline Family history of genetic syndrome & & $<.001$ & & $<.001$ & & $<.001$ & & 1.00 & & .10 \\
\hline Present & 68.3 & & 70.6 & & 68.4 & & 0.0 & & 75.0 & \\
\hline Absent & 28.6 & & 29.4 & & 28.9 & & 10.0 & & 29.8 & \\
\hline $\begin{array}{l}\text { Family history of congenital } \\
\text { structural heart disease }\end{array}$ & & .26 & & .094 & & 1.00 & & & & .65 \\
\hline Present & 38.8 & & 46.7 & & 30.8 & & & & 16.7 & \\
\hline Absent & 30.2 & & 30.3 & & 30.7 & & 10.0 & & 34.7 & \\
\hline Family history of arrhythmia & & .46 & & .66 & & .73 & & & & .29 \\
\hline Present & 21.1 & & 40.0 & & 20.0 & & & & 0.0 & \\
\hline Absent & 30.8 & & 31.8 & & 30.8 & & 10.0 & & 34.7 & \\
\hline CHF at diagnosis & & .53 & & .01 & & .75 & & .35 & & .25 \\
\hline Present & 34.3 & & 51.9 & & 32.2 & & 8.3 & & 38.1 & \\
\hline Absent & 32.2 & & 32.6 & & 34.1 & & 29.4 & & 25.6 & \\
\hline
\end{tabular}

One patient with an unknown cause had a missing type and was not included in the type columns but was included in the "All" column

a Monte Carlo approximation of Fisher's exact $P$ value.

b Mantel-Haenszel $\chi^{2} P$ value.

Friedreich's ataxia. A known cause was almost twice as likely in the absence of left ventricular outflow tract obstruction as in its presence $(39.2 \%$ vs $22.8 \% ; P=$ .012 ). No other echocardiographic or electrocardio- graphic variables were associated with a known cause for patients with HCM.

For patients with DCM, those with a known cause tended to have less-severe cardiac disease than did pa- 
TABLE 3 Rates of Known Causes of Cardiomyopathy Among 916 Children From the PCMR Retrospective Cohort, According to Selected Categorical Echocardiographic Characteristics, Classified According to Type

\begin{tabular}{|c|c|c|c|c|c|c|c|c|c|c|}
\hline \multirow[t]{2}{*}{ Characteristic } & \multicolumn{2}{|c|}{ All $(n=916)$} & \multicolumn{2}{|c|}{$\mathrm{HCM}(n=313)$} & \multicolumn{2}{|c|}{$\mathrm{DCM}(n=492)$} & \multicolumn{2}{|c|}{$\mathrm{RCM}(n=29)$} & \multicolumn{2}{|c|}{$\begin{array}{l}\text { Other or Mixed } \\
\text { Cardiomyopathy } \\
\quad(n=81)\end{array}$} \\
\hline & $\begin{array}{c}\text { \% Known } \\
\text { Causes }\end{array}$ & $P$ & $\begin{array}{c}\% \text { Known } \\
\text { Causes }\end{array}$ & $P$ & $\begin{array}{c}\% \text { Known } \\
\text { Causes }\end{array}$ & $P$ & $\begin{array}{c}\text { \% Known } \\
\text { Causes }\end{array}$ & $P$ & $\begin{array}{c}\% \text { Known } \\
\text { Causes }\end{array}$ & $P$ \\
\hline Echocardiography & & .86 & & .25 & & .56 & & 1.00 & & 1.00 \\
\hline Done & 33.3 & & 34.9 & & 33.1 & & 21.4 & & 32.9 & \\
\hline Not done & 35.0 & & 47.6 & & 23.1 & & 0.0 & & 20.0 & \\
\hline Mitral regurgitation & & $.03^{a}$ & & & & $.01^{\mathrm{a}}$ & & $.89^{a}$ & & $.07^{\mathrm{a}}$ \\
\hline None & 37.2 & & 36.8 & & 41.6 & & 15.4 & & 29.4 & \\
\hline Mild & 31.4 & & 32.5 & & 31.3 & & 33.3 & & 29.0 & \\
\hline Moderate & 30.2 & & 13.3 & & 31.3 & & 0.0 & & 60.0 & \\
\hline Severe & 23.1 & & & & 14.3 & & 0.0 & & 75.0 & \\
\hline Tricuspid regurgitation & & $.07^{\mathrm{a}}$ & & & & $.06^{a}$ & & & & $.87^{a}$ \\
\hline None & 34.3 & & 34.9 & & 35.4 & & 21.4 & & 29.8 & \\
\hline Mild & 36.2 & & 34.0 & & 36.0 & & 25.0 & & 50.0 & \\
\hline Moderate & 21.1 & & 0.0 & & 22.2 & & 0.0 & & 25.0 & \\
\hline Severe & 13.3 & & & & 14.3 & & & & 0.0 & \\
\hline Right atrial dilation & & .02 & & 1.00 & & .02 & & 1.00 & & 1.00 \\
\hline Present & 23.2 & & 33.3 & & 19.2 & & 22.7 & & 30.8 & \\
\hline Absent & 35.1 & & 34.3 & & 36.1 & & 20.0 & & 34.4 & \\
\hline Left atrial dilation & & .07 & & .07 & & .35 & & 1.00 & & 1.00 \\
\hline Present & 28.9 & & 16.7 & & 31.0 & & 24.0 & & 32.0 & \\
\hline Absent & 35.5 & & 35.8 & & 35.7 & & 0.0 & & 34.7 & \\
\hline Right ventricular outflow tract obstruction & & .85 & & .54 & & & & .22 & & 1.00 \\
\hline Present & 31.3 & & 28.6 & & & & 100 & & 33.3 & \\
\hline Absent & 33.9 & & 35.6 & & 34.0 & & 19.2 & & 32.9 & \\
\hline Left ventricular outflow tract obstruction & & .03 & & .01 & & .55 & & & & 1.00 \\
\hline Present & 22.6 & & 22.8 & & 0.0 & & & & 50.0 & \\
\hline Absent & 35.0 & & 39.2 & & 34.3 & & 22.2 & & 32.4 & \\
\hline
\end{tabular}

One patient with an unknown cause had a missing type and was not included in the type columns but was included in the "All" column

a Mantel-Haenszel $\chi^{2} P$ value.

tients with an unknown cause, as evidenced by several variables. The patients with DCM with a known cause had lower mean end diastolic dimension $z$ scores (3.49 vs 4.56; $P<.001$ ), lower mean end systolic dimension $z$ scores (5.32 vs 6.40; $P<.001$ ), and higher mean fractional shortening $z$ scores $(-7.99$ vs $-8.99 ; P=.009)$ (Table 4). The most common causes for patients with cardiac dimensions below the sample average were myocarditis and Duchenne muscular dystrophy.

A known cause of DCM was nearly 3 times more likely in the absence of mitral valve regurgitation than in the presence of severe regurgitation $(41.6 \%$ vs $14.3 \%$; $P$ $=.010)$. Similar patterns were seen for tricuspid regurgitation $(P=.06)$ and right atrial dilation $(P=.02)$. Patients with DCM attributable to a specific cause also had a lower mean heart rate (124 beats per minute vs 136 beats per minute; $P<.001$ ), which was the only significant electrocardiographic finding for any of the functional types of cardiomyopathy.

The only significant echocardiographic finding for patients with RCM was a higher mean shortening fraction $z$ score for those with a known cause, compared with those without a known cause (1.57 vs -1.26 ; $P=.04$ ). There were no significant echocardiographic findings for the group with other or mixed cardiomyopathy, perhaps because of the heterogeneity of this group.

\section{Associations Between Causal Status and Testing for Cause of Cardiomyopathy}

Within each functional type of cardiomyopathy, the overall rates of known causes were similar for patients who had undergone any causal testing and those who had not. Children with HCM underwent testing at the time of cardiomyopathy diagnosis approximately one half as often as did those with other types of cardiomyopathy. The lack of an association between a known cause and diagnostic laboratory testing might have been the result of including children whose disease cause is determined typically through other means. Therefore, analyses were conducted after the exclusion of children with a neuromuscular disorder, familial isolated cardiomyopathy, or malformation syndrome (Table 5). Patients with neuromuscular disease $(n=68)$ were excluded because typically musculoskeletal disease is identified before cardiomyopathy develops, and test results obtained before the diagnosis of cardiomyopathy were not collected in the PCMR. Patients with familial isolated cardiomyopathy $(n=74)$ or a malformation 
syndrome $(n=27)$ were also excluded, because typically these diagnoses are made through echocardiographic evaluation of other family members and physical examination, respectively.

In this subgroup of patients with HCM, each class of testing (metabolic blood or urine testing, biopsy, viral serologic testing or culture, or chromosomal analysis) was associated significantly with a higher rate of known causes. The most important metabolic urine tests were measurements of ketones and amino acids, with the odds of a known cause being 4 times the odds of a known cause in the absence of such testing. Several metabolic blood tests, including carnitine, creatine phosphokinase, lactate, ammonia, and pyruvate measurements, were associated significantly with a known cause (odds ratios [OR]: 4-7). Skeletal muscle biopsy was more informative than endomyocardial biopsy, but neither was performed very often for children with HCM. Interestingly, $47.8 \%$ of children with viral serologic testing or culture had a cause established, which was significantly higher than the $8.6 \%$ known cause rate for those without viral serologic testing or culture, despite the fact that none of the patients with viral myocarditis had HCM. All of these patients with HCM were diagnosed as having various inborn errors of metabolism, which indicates that viral testing might be a proxy for causal testing in general or that their cardiomyopathy might have presented in the setting of metabolic decompensation triggered by a viral infection. Finally, chromosomal analysis was associated with known cause (OR: 6.56; $P=$ $.01)$.

For the DCM subgroup, metabolic urine testing, biopsy, and viral serologic or culture testing were all associated with an increased rate of known causes, but metabolic blood testing and chromosomal analysis were not. The urine results were driven by testing for ketones, which was associated with an approximately twofold increase in the rate of known causes. In contrast, plasma pyruvate testing was associated with a threefold lower rate of known cause. Endomyocardial biopsy was a significant predictor (odds ratio: 5.69; $P<.001$ ), whereas skeletal muscle biopsy was not $(P=.78)$. The most common cause identified through endomyocardial biopsy was viral myocarditis. Viral serologic or culture testing more than doubled the rate of known causes (28.6\%, compared with $12.7 \%$ known cause for those without this test).

For the RCM subgroup, there were only 22 patients with testing data after exclusions and none had a known cause, despite the fact that 16 of the patients underwent some form of testing. For the other or mixed cardiomyopathy group, no test was associated significantly with an increased rate of known cause. The test that came closest to achieving significance was skeletal muscle biopsy $(66.7 \%$ vs $17.2 \%$, with and without biopsy; $P=$ $.09)$. Metabolic blood testing in this small sample also 
TABLE 5 Crude Rates of Testing for Cause of Cardiomyopathy and Rates of Known Causes of Cardiomyopathy, According to Testing Status, for Patients From the PCMR Retrospective Cohort, Excluding Patients With Familial Isolated Cardiomyopathy, Neuromuscular Disorders, and Malformation Syndromes

\begin{tabular}{|c|c|c|c|c|c|c|}
\hline \multirow[t]{2}{*}{ Type of Testing } & \multirow[t]{2}{*}{ No. } & \multirow[t]{2}{*}{ Testing, \% } & \multicolumn{2}{|c|}{$\%$ Known Causes } & \multirow[t]{2}{*}{ Odds Ratio } & \multirow[t]{2}{*}{$P$} \\
\hline & & & Testing Done & $\begin{array}{l}\text { No Testing } \\
\text { Done }\end{array}$ & & \\
\hline \multicolumn{7}{|l|}{$\operatorname{HCM}(n=230)^{\mathrm{a}}$} \\
\hline Metabolic urine testing & 225 & 22.2 & 28.0 & 8.6 & 4.15 & .001 \\
\hline Metabolic blood testing & 221 & 26.2 & 34.5 & 5.5 & 9.01 & $<.001$ \\
\hline Biopsy & 227 & 8.8 & 45.0 & 10.1 & 7.25 & $<.001$ \\
\hline Endomyocardial & 230 & 4.4 & 30.0 & 12.3 & 3.06 & .13 \\
\hline Skeletal & 227 & 4.4 & 60.0 & 11.1 & 12.06 & $<.001$ \\
\hline Viral serologic testing or culture & 221 & 10.4 & 47.8 & 8.6 & 9.76 & $<.001$ \\
\hline Chromosome analysis & 224 & 4.9 & 45.5 & 11.3 & 6.56 & .01 \\
\hline Any testing & $219^{b}$ & 36.5 & 27.5 & 4.3 & 8.41 & $<.001$ \\
\hline \multicolumn{7}{|l|}{$\operatorname{DCM}(n=422)^{c}$} \\
\hline Metabolic urine testing & 406 & 37.7 & 28.1 & 19.0 & 1.67 & .04 \\
\hline Metabolic blood testing & 407 & 51.6 & 24.8 & 18.8 & 1.42 & .15 \\
\hline Biopsy & 419 & 47.0 & 35.5 & 9.9 & 5.01 & $<.001$ \\
\hline Endomyocardial & 421 & 44.7 & 37.2 & 9.4 & 5.69 & $<.001$ \\
\hline Skeletal & 419 & 4.5 & 15.8 & 22.3 & 0.66 & .70 \\
\hline Viral serologic testing or culture & 408 & 55.6 & 28.6 & 12.7 & 2.76 & $<.001$ \\
\hline Chromosome analysis & 414 & 2.4 & 10.0 & 22.0 & 0.39 & .70 \\
\hline Any testing & $410^{d}$ & 78.3 & 26.2 & 6.7 & 4.90 & $<.001$ \\
\hline \multicolumn{7}{|c|}{ Other or mixed cardiomyopathy $(n=67)^{\mathrm{e}}$} \\
\hline Metabolic urine testing & 65 & 46.2 & 20.0 & 17.1 & 1.21 & 1.00 \\
\hline Metabolic blood testing & 65 & 53.9 & 25.7 & 10.0 & 3.12 & .12 \\
\hline Biopsy & 67 & 44.8 & 26.7 & 13.5 & 2.33 & .22 \\
\hline Endomyocardial & 67 & 44.8 & 26.7 & 13.5 & 2.33 & .22 \\
\hline Skeletal & 67 & 4.5 & 66.7 & 17.2 & 9.64 & .10 \\
\hline Viral serologic testing or culture & 67 & 44.8 & 16.7 & 21.6 & 0.73 & .76 \\
\hline Chromosome analysis & 67 & 7.5 & 20.0 & 19.4 & 1.04 & 1.00 \\
\hline Any testing & $67^{f}$ & 68.7 & 21.7 & 14.3 & 1.67 & .74 \\
\hline
\end{tabular}

The RCM group ( $n=22$ ) was too small for any meaningful comparisons and was not included in this table.

a See Methods for definitions of testing components. Testing component information was positive or complete for 219 patients. One patient did not have any testing information available.

${ }^{\mathrm{b}}$ A total of 80 (36.5\%) of 219 patients underwent $\geq 1$ form of testing.

c See Methods for definitions of testing components. Testing component information was positive or complete for 410 patients. Two patients did not have any testing information available.

d A total of 321 (78.3\%) of 410 patients underwent $\geq 1$ form of testing.

e See Methods for definitions of testing components. Testing component information was positive or complete for 67 cases. One patient did not have any testing information available.

${ }^{f}$ A total of 46 (68.7\%) of 67 patients underwent $\geq 1$ form of testing.

suggested utility $(25.7 \%$ known cause, compared with $10.0 \%$ known cause for those without such testing; $P=$ $.12)$.

Multivariate modeling was conducted to identify which classes of blood or urine tests or biopsies were independent predictors of a known cause for patients with HCM or DCM, after adjustment for each other as well as 3 covariates, namely, age at cardiomyopathy diagnosis, presence versus absence of CHF at cardiomyopathy diagnosis, and geographic region (Northeast versus all other regions). These covariates were chosen because, for some or all types of cardiomyopathy, they were found to be associated with both causal status and the likelihood that testing was conducted. For patients with HCM, the general finding was that, as a group, blood and urine tests were associated independently with establishing a cause (OR: 4.15; 95\% confidence interval [CI]: 1.43-12.05; $P=.009$ ) but biopsy was not (OR: $1.75 ; P=.37)$. Interestingly, viral serologic testing or culture and metabolic blood and urine testing (OR: 3.54; $P=.01$ ) were each significant when examined separately in covariate-adjusted models for cause among patients with HCM, but the strongest covariate-adjusted model contained only viral serologic testing or culture (OR: 6.42; 95\% CI: 2.14-19.28; $P<.001$ ). This paradox suggests that, in this sample, these 2 classes of tests were most likely conducted simultaneously. When skeletal muscle biopsy was added to this model, it was not associated significantly with causal status (OR: 2.97; $P=$ .20). In the DCM cohort, both viral serologic testing or culture (OR: $1.81 ; 95 \%$ CI: $1.81-3.19 ; P=.04$ ) and endomyocardial biopsy (OR: 4.84; 95\% CI: $2.71-8.66$; $P$ $<.001)$ were associated independently with establishing a cause.

\section{DISCUSSION}

Only one third of children had a known cause at the time of cardiomyopathy diagnosis, with the remaining 
two thirds of cases being classified as idiopathic. We hypothesized that children with a known cause of cardiomyopathy might share certain patient, disease, and clinical practice characteristics that would distinguish them from children with idiopathic cardiomyopathy. Identifying these variables might lead to better diagnostic strategies and ultimately improved outcomes from cause-specific treatments. Knowing the cause of cardiomyopathy is important, not only for guiding the specialists involved in the child's care but also for providing families with accurate recurrence risk assessments, because many causes have a genetic basis.

After exclusion of children with conditions diagnosed generally through other means and adjustment for confounders, multivariate modeling revealed that only blood and urine testing was important for establishing a cause for the vast majority of patients with HCM. For patients with DCM, endomyocardial biopsy and viral serologic testing or culture were important, which indicates that each can identify some causes of DCM that the other cannot. In clinical practice, however, biopsy is often performed later in the diagnostic evaluation, once urine and blood testing are complete, because of its invasiveness and patient instability at presentation. Furthermore, some centers do not perform endomyocardial biopsies. Whether a patient had medical insurance did not affect the rate of causal diagnosis, which suggests that, once cardiomyopathy is identified, access to medical care is not a limiting factor.

Nearly identical proportions of cardiomyopathy cases with unknown causes were observed in the retrospective $(66.7 \%$ of 916 patients) and prospective regional (68.7\% of 467 children) arms of the PCMR, despite differences in the period of diagnosis (1990-1995 versus 1996-1999) and geography (United States and Canada versus New England and Central Southwest regions of the United States). These results are similar to the Australian experience, in which $57 \%$ of cases of primary cardiomyopathy presenting in 314 children $<10$ years of age from 1987 to 1996 were classified as being idiopathic. ${ }^{2}$ The findings suggest that there has been no marked improvement in the diagnostic evaluation of these children in the past decade, which is perplexing, given the increasing number of metabolic, genetic, and viral causes of cardiomyopathy that have been identified during the same period. ${ }^{4,5,19-22}$ Although some diagnostic tests have not been adopted quickly in clinical practice, our findings (Table 5) indicate that available testing is being underused and that increased testing might identify a cause for a greater proportion of these children.

An excess of boys with cardiomyopathy was found $(58.2 \%)$, which might be attributable to X-linked genetic disorders. ${ }^{1}$ The 2 best-known causes of X-linked cardiomyopathy are defects in the genes encoding dystrophin and tafazzin. Although each is associated with a multisystem neuromuscular disease (Duchenne/Becker muscular dystrophies and Barth syndrome, respectively), each can cause isolated DCM. Certainly, testing for these conditions seems prudent for boys with idiopathic DCM. Interestingly, girls were more likely than boys to have a known HCM cause, and this likelihood was related to an excess of familial isolated HCM. One possible explanation is gender-dependent penetrance, perhaps related to hormonal factors.

Myocarditis was the leading individual cause, accounting for $9.7 \%$ of all children (89 of 916 children), $18.1 \%$ of those with DCM (89 of 492 children), $29.2 \%$ of those with known causes (89 of 305 children), and $51.6 \%$ of those with DCM and known causes (89 of 161 children). The true frequency of viral myocarditis in all of these studies might be even higher, because the diagnosis required a probable or confirmed diagnosis based on the Dallas histologic criteria. Endomyocardial biopsy should be considered strongly for children with DCM for definitive diagnosis of viral myocarditis relatively early in the diagnostic evaluation (ie, within the first 1 month), because the histologic findings of myocarditis can regress relatively quickly. Some cardiotropic viruses, such as adenovirus, do not produce the typical lymphocytic infiltration associated with myocarditis. In such cases, detecting the viral genome through polymerase chain reaction in the myocardium or tracheal aspirates may be necessary for diagnosis. ${ }^{20,23}$ The roles of the immune response, viral proteases that cleave dystrophin, and apoptosis in the pathophysiologic processes of viral myocarditis are being understood increasingly and are forming the basis of current and future treatments. ${ }^{9,12,24-26}$

The prevalence rates of inborn errors of metabolism in the retrospective cohort of the PCMR were $5.1 \%$ of all children and $15.4 \%$ of those with a known cause, which were lower than values reported in other pediatric cardiomyopathy studies. The Australian study found an inborn error of metabolism for $8.9 \%$ of all children with cardiomyopathy and $20.9 \%$ of those with a known cause. ${ }^{2}$ These rates might be higher because of the younger ages of Australian children recruited for study. In a multicenter study performed in the United States, $20 \%$ of 221 children with cardiomyopathy were suspected of having a metabolic disorder and were treated empirically with carnitine. ${ }^{11}$ Although the children who received carnitine tended to be younger and sicker, they had a lower mortality rate and achieved the same clinical status as the other children. A European study found that $22.4 \%$ of 58 children diagnosed initially as having idiopathic cardiomyopathy had an inborn error of metabolism identified after systematic screening. ${ }^{27}$ Nearly one half of the diagnoses $(n=6)$ involved mitochondrial respiratory chain defects that were limited to the myocardium and required direct testing of endomyocardial biopsies. These studies suggest that some of the children in the PCMR who were diagnosed as having idiopathic 
cardiomyopathy might have had an unrecognized inborn error of metabolism.

Mitochondrial disorders involving $\geq 1$ respiratory chain enzyme deficiency can manifest as either HCM or DCM in children. This group of diagnoses typically is confirmed through skeletal muscle biopsy, but only a small number of subjects $(4 \%-5 \%)$ with each cardiomyopathy type underwent this form of testing in the PCMR. Consequently, there were insufficient subjects to allow a definitive conclusion about its lack of utility for children with DCM. Given the low rate of mitochondrial respiratory enzyme testing performed in our study, skeletal muscle biopsy might be helpful for children with HCM and DCM if no other cause is identified.

Familial isolated cardiomyopathy was a relatively common diagnosis in the PCMR, accounting for $24 \%$ of children with known causes, of which $42 \%$ were HCM, $34 \%$ DCM, $8 \%$ RCM, and $16 \%$ other or mixed cardiomyopathy. For adults, HCM is considered to be an autosomal dominant, genetically heterogeneous disorder caused by defects in sarcomeric proteins. ${ }^{28}$ By comparison, only $30 \%$ of DCM cases are thought to be familial, ${ }^{29}$ with causes being largely unknown but likely to involve the cytoskeleton. In one study, 63\% of 197 unrelated adults with familial or sporadic HCM had mutations identified among 9 genes coding for sarcomeric proteins. ${ }^{30}$ Interestingly, 6 of the families had affected relatives with 2 mutations, either in the same gene (homozygous or compound heterozygous) or in different genes (double heterozygous). Compared with the adults with only 1 identified mutation, these patients had an earlier age of onset (ranging from infancy to early adulthood), more severe hypertrophy, and a worse prognosis, which suggests a gene-dosage effect. Clearly, a similar systematic study of children with HCM needs to determine whether a substantial proportion of familial or idiopathic disease is caused by the presence of 1 or 2 mutations in sarcomeric genes. Our study showed that little genetic testing was performed for children with HCM and their families. With the recent introduction of clinical genetic testing for familial HCM and $\mathrm{DCM}^{31}$ and with the PCMR providing a link to patient data, this hypothesis can now be tested.

The true number of familial cases of cardiomyopathy in the PCMR is likely to be underestimated, because not all families undergo thorough evaluations, some familial cases may go undetected because of transient or agedependent penetrance, ${ }^{28}$ and the proband may be the first family member to exhibit clinical symptoms (ie, a sporadic case). A detailed family history and echocardiographic studies of first-degree relatives, including asymptomatic relatives, are important for diagnosis. Identifying familial cardiomyopathy serves the dual purpose of avoiding additional causal testing and alerting other family members of their disease status and risk.

There were some limitations of the study. The anal- yses reflect causal testing performed only during the month after the diagnosis of cardiomyopathy. The finding that the rate of known causes increased by only $6 \%$ after 1 year (data not shown) indicates that most causes are identified at earlier time points. The study revealed an association between testing and causal status, not cause and effect, and the temporal relationship between testing and causal status was not always clear. Certain causes that typically are known before the diagnosis of cardiomyopathy (eg, neuromuscular disorders, familial isolated cardiomyopathy, and malformation syndromes) might confound the interpretation of the utility of testing and were excluded from these analyses; therefore, our study does not address the value of causal testing in these groups. In addition, children with an inborn error of metabolism might have undergone some testing for monitoring rather than diagnostic purposes. However, the 2 independent predictors of known cause revealed by our analyses, namely, biopsy (for patients with DCM only) and viral serologic testing or culture, typically are used to establish a cause. Neither would likely be performed for patients with an existing condition known to be associated with cardiomyopathy.

This study was based on detailed data collected between 1990 and 1995 and may not reflect current clinical practice. However, the nearly identical rates of idiopathic cardiomyopathy in the retrospective and prospective regional cohorts of the PCMR suggest little change in diagnostic evaluations during this 10-year period.

\section{CONCLUSIONS}

On the basis of our results, we recommend that the diagnostic evaluation of cardiomyopathy in children include a thorough family history and echocardiographic testing of first-degree relatives (for familial isolated cardiomyopathy), a detailed dysmorphology and medical examination (for malformation syndromes), and appropriate laboratory and histologic testing (for inborn errors of metabolism, neuromuscular disorders, and viral myocarditis). For children for whom a cause has not been identified after blood and urine testing, endomyocardial biopsy for children with DCM should be considered strongly. For certain causes of HCM for which blood and urine testing has been inconclusive and for cases in which a mitochondrial disorder is suspected, skeletal muscle biopsy should be considered.

\section{ACKNOWLEDGMENTS}

The PCMR is supported by a grant funded by the National Heart, Lung, and Blood Institute (grant R01 HL53392, to S.E.L.). The work is also funded in part by grants from the National Institutes of Health (grant P01 HL67155, to J.A.T.; grant R01 HL78522, to S.E.L.; grant R01 HL72705, to S.E.L.; grant R01 CA79060, to S.E.L.; grant P01 CA68484, to S.E.L.; and grant N01 HR96041, 
to S.E.L.), the Parker Family Foundation (S.E.L.), the John Patrick Albright Foundation (J.A.T.), the Abby Glaser Children's Heart Fund (J.A.T.), the Amanda McPherson Foundation (J.A.T.), the Glover-Crask Trust (S.E.L.), the David B. Perini, Jr, Quality of Life Program (S.E.L.), the Lance Armstrong Foundation (S.E.L.), the Muscular Dystrophy Association (S.E.L.), the Greenberg May Foundation (S.E.L.), the LeDucq Foundation (S.E.L.), and the Children's Cardiomyopathy Foundation (G.F.C., L.A.S., J.A.T., and S.E.L.). J.A.T. is supported by the Texas Children's Hospital Foundation Chair in Pediatric Cardiac Research

Participants in the PCMR are as follows: University of Miami (administrative coordinating center): S. Lipshultz (principal investigator), J. Wilkinson, J. Alvarez; New England Research Institutes (data coordinating center): L. Sleeper (principal investigator), A. Lowe, P. Nash, N. Pophali, L. Cuniberti, J. McGill; Boston Children's Hospital: S. Colan (principal investigator), G. Cox, J. Messere; Brigham and Women's Hospital: E. J. Orav; Baylor College of Medicine, Texas Children's Hospital: J. Towbin (principal investigator), D. Cline, S. Clunie; Albany Medical College: P. Lurie; Scientific Advisory Council (May 1996 to May 2001): L. Benson, S. Kaplan, T. Klitzner, J. Krischer, W. Lewis, A. Strauss (chair), G. Pearson, C. Weinstein; Observational Study Monitoring Board (May 2001 to May 2005): H. Gutgesell, J. Krischer (chair), C. Morris, J. Norman, G. Van Hare, G. Pearson (ex officio); participating clinical centers: Central Southwest region: Arkansas: Arkansas Children's Hospital (Little Rock, AR): E. Frazier (principal investigator), R. Morrow, P. Seib; Oklahoma: University Hospital (Oklahoma City, OK): K. Ward (principal investigator), S. Baker; Texas: Cook Children's Heart Center, Pediatric Cardiology Associates (Fort Worth, TX): L. Roten (principal investigator), K. Hart; Southeast Texas Cardiology Associates (Beaumont, TX): Vijay Kusnoor (principal investigator), Jan Reddell; South Texas Pediatric Cardiology Associates, Driscoll Children's Hospital (Corpus Cristi, TX): J. Pastorek (principal investigator), J. Rebok; Children's Heart Center of West Texas (Lubbock, TX): J. Park (principal investigator); Presbyterian Professional Building III, Department of Pediatrics (Dallas, TX): D. Wright (principal investigator), A. Smith; Texas Tech University, Department of Pediatrics (El Paso, TX): J. Schuster (principal investigator), S. Moeller; Pediapex, Heart Center for Children (Dallas, TX): J. Koa (principal investigator); Healthcare Professional Associates (Amarillo, TX): D. Luckstead (principal investigator); Pediatric Cardiology Associates (San Antonio, TX): K. Bloom (principal investigator), Julie Brown; University of Texas Medical Branch at Galveston, Children's Hospital (Galveston, TX): W. Pearl (principal investigator), Ashraf Aly; Children's Heart Network (San Antonio, TX): J. Rogers, M. Gaenzel; Children's Cardiology Associates (Austin, TX): S. Rowe (principal investigator), L. Davis;
Baylor College of Medicine, Texas Children's Hospital (Houston, TX): J. Towbin (principal investigator), S. Clunie; University of Texas Health Science Center, Pediatric Cardiology (Houston, TX): M. Thaper (principal investigator), T. Yover; University of Texas, Southwestern Medical Center of Dallas, Children's Medical Center, Division of Cardiology (Dallas, TX): M. Lemler (principal investigator), H. Carron; Department of Pediatrics, Wilford Hall Medical Center (Lackland Air Force Base, TX): K. Milhoan (principal investigator), D. Bush, W. Marek; New England region: Connecticut: Pediatric Cardiology Associates, Yale University, Pediatric Cardiology (New Haven, CT): P. Bowers (principal investigator), W. Hellenbrand; Pediatric Cardiology Associates, Connecticut Children's Medical Center (Hartford, CT): H. Leopold (principal investigator), K. Mazzarella; Maine: Eastern Maine Medical Center, Pediatric Medicine, Pediatric Cardiology (Bangor, ME): A. Gilladoga (principal investigator), K. Mazerolle; Pediatric Cardiology Associates, Maine Medical Center (Portland, ME): M. Hourihan (principal investigator); Massachusetts: Floating Hospital for Children, Tufts University, School of Medicine, Department of Pediatrics (Boston, MA): T. Meade; Children's Hospital/Harvard Medical School (Boston, MA): S. Colan (principal investigator), J. Messere; Massachusetts General Hospital, Harvard Medical School (Boston, MA): M. DeMoore (principal investigator), W. Jennings; University of Massachusetts, Department of Pediatrics (Worcester, MA): P. Pollack (principal investigator), N. Hagberg; New Hampshire: Regional Program in Pediatric Cardiology, Dartmouth-Hitchcock Medical Center (Lebanon, NH): N. Drucker (principal investigator), K. Frechette; Hitchcock Clinic, Manchester Division, Dartmouth-Hitchcock Medical Center, Elliot Hospital (Manchester, NH): S. Rockenmacher (principal investigator), E. Taylor; Rhode Island: Hasbro Children's Hospital, Pediatric Cardiology (Providence, RI): R. Corwin (principal investigator); Rhode Island Hospital, Pediatric Cardiology (Providence, RI): K. Rotondo (principal investigator), M. Romoli; Rhode Island Hospital, Brown University, School of Medicine, Division of Pediatric Cardiology (Providence, RI): J. Werner (principal investigator); Anchor Medical Associates, Section of Cardiology (Lincoln, RI): N. Beraha (principal investigator); Pediatric Cardiology (Providence, RI): P. Rompf (principal investigator); Vermont: Fletcher Allen Health Care, University of Vermont (Burlington, VT): N. Drucker (principal investigator), S. Yeager; other US sites: Alabama: University of Alabama (Birmingham, AL): F. Pearce (principal investigator); California: Loma Linda University Medical Center (Loma Linda, CA): R. Larsen (principal investigator), L. Wood; Children's Hospital of Los Angeles (Los Angeles, CA): A. Lewis (principal investigator), M. Hsieh; Children's Associated Medical Group (San Diego, CA): M. Cocalis (principal investigator), T. McLees-Palinkas; University of California, Davis, 
Medical Center (Sacramento, CA): M. Parrish (principal investigator), C. Buckley; University of California, San Diego, Medical Group (San Diego, CA): A. Rothman (principal investigator), B. McCormick; Children's Hospital of Orange County (Orange, CA): M. Singer (principal investigator); University of California, Los Angeles, Children's Hospital (Los Angeles, CA): J. Alejos (principal investigator), C. Burch; University of California, Irvine, Medical Center (Orange, CA): K. Manning; Florida: University of Florida College of Medicine (Gainesville, FL): B. Byrne (principal investigator), F. Fricker (principal investigator), C. Nixon; (Miami, FL): R. Zakheim (principal investigator), M. Perez; Jackson Memorial Hospital (Miami, FL): P. Rusconi (principal investigator), L. Marilla; Georgia: Children's Heart Center (Atlanta, GA): M. Strieper (principal investigator); Illinois: Children's Memorial Hospital (Chicago, IL): E. Pahl (principal investigator), K. Lazewski, T. Johnson; University of Illinois-Chicago (Chicago, IL): S. Kumar (principal investigator), J. Misner; Loyola University Medical Center (Maywood, IL): E. Fisher (principal investigator); Iowa: Children's Hospital of Iowa (Iowa City, IA): J. Morriss (principal investigator); Kansas: Wichita Clinic (Wichita, $\mathrm{KS}$ ): S. Allen (principal investigator); University of Kansas Medical Center (Kansas City, KS): K. Goertz (principal investigator), B. Rankin; Kentucky: University of Kentucky College of Medicine (Lexington, KY): J. Noonan (principal investigator); Louisiana: Tulane University Hospital and Clinic (New Orleans, LA): W. Hanson; Maryland: University of Maryland Medical System (Baltimore, MD): M. Salim (principal investigator); Johns Hopkins Hospital (Baltimore, MD): J. Scheel (principal investigator); Michigan: Children's Hospital of Michigan (Detroit, MI): R. Ross (principal investigator), L. Deutschman; Michigan State University (East Lansing, MI): M. Goble (principal investigator); Minnesota: Children's Heart Clinic (Minneapolis, MN): G. Wright (principal investigator); Missouri: Cardinal Glennon Children's Hospital (St Louis, MO): I. Balfour (principal investigator); St Louis Children's Hospital (St Louis, MO): C. Canter (principal investigator), T. Boschert, L. Cowan, S. Lassa-Claxton; Nebraska: Lincoln Pediatric Cardiology (Omaha, NE): A. Martin (principal investigator), S. Rorie; Nevada: Children's Heart Center of Las Vegas (Las Vegas, NV): W. Evans (principal investigator), R. Lange; New Mexico: Children's Hospital Heart Center (Albuquerque, NM): J. Waldman (principal investigator), W. Wiggins; New York: School of Medicine (Stony Brook, NY): T. Biancaniello (principal investigator); New York University Hospital Center (New York, NY): M. Artman (principal investigator), S. McGuire; Mount Sinai Medical Center (New York, NY): B. Gelb (principal investigator); Children's Hospital (Buffalo, NY): R. Gingell (principal investigator); New York Weill Cornell Medical Center (New York, NY): M. Schiller (principal investigator); State University of New York Health Sci- ence Center at Brooklyn (Brooklyn, NY): J. Sharma (principal investigator); Capital District Cardiology Associates (Albany, NY): H. Velvis (principal investigator); Montefiore Medical Center (Bronx, NY): C. Steeg (principal investigator); New York Medical Center (Valhalla, NY): U. Krishnan (principal investigator); Children's Hospital of New York (New York, NY): D. Hsu (principal investigator), D. Servedio; Strong Memorial Hospital (Rochester, NY): W. Harmon (principal investigator), M. Rees; North Carolina: The Sanger Clinic (Charlotte, NC): D. Riopel (principal investigator), T. Morse; Duke University Medical Center (Durham, NC): A. Nawrocki (principal investigator); East Carolina University School of Medicine (Greenville, NC): C. Sang (principal investigator), S. Welch; Ohio: Columbus Children's Hospital (Columbus, $\mathrm{OH}$ ): T. Feltes (principal investigator), T. Hoffman (principal investigator), J. Mueller, L. Perkins; Children's Hospital Heart Center (Cincinnati, OH): T. Kimball (principal investigator), R. Spicer (principal investigator); Cleveland Clinic Children's Hospital (Cleveland, $\mathrm{OH}$ ): G. Rosenthal (principal investigator), C. Nasman; Metro Health Medical Center (Cleveland, OH): J. Batke (principal investigator); Oregon: Oregon Health Sciences University (Portland, OR): M. Reller (principal investigator), L. Parsley; Pennsylvania: Children's Hospital of Pittsburgh (Pittsburgh, PA): B. Keller (principal investigator), S. Webber (principal investigator), S. Tamburro, P. Bowman, D. Thomas; Tennessee: Vanderbilt University Medical Center (Nashville, TN): D. Dodd (principal investigator), J. Burger; T.C. Thompson Children's Hospital (Chattanooga, TN): J. Morgan (principal investigator); Virginia: Medical College of Virginia (Richmond, VA): W. Moskowitz (principal investigator); Utah: Primary Children's Medical Center (Salt Lake City, UT): R. Shaddy (principal investigator), R. Holdridge; West Virginia: Marshall University (Huntington, WV): M. Heydarian (principal investigator), A. Preston; Wisconsin: Children's Hospital of Wisconsin (Milwaukee, WI): S. Berger (principal investigator); Canadian sites: Alberta: University of Alberta Hospital (Edmonton, Alberta): J. Dyck (principal investigator), K. McCarthy; Alberta Children's Hospital (Calgary, Alberta): D. Patton (principal investigator); British Columbia: British Columbia Children's Hospital (Vancouver, British Columbia): D. Human (principal investigator), P. Tran; Ontario: Hospital for Sick Children (Toronto, Ontario): L. Benson (principal investigator), S. Aiello, N. Slater; Children's Hospital of Eastern Ontario (Ottawa, Ontario): J. Lougheed (principal investigator), L. Lynch; Quebec: Children's Hospital of Montreal (Montreal, Quebec): C. Rohlicek (principal investigator); Saskatchewan: Royal University Hospital (Saskatoon, Saskatchewan): M. Tyrrell (principal investigator).

We are grateful for the assistance of the PCMR staff and participating clinical centers that contributed patient data. 


\section{REFERENCES}

1. Lipshultz SE, Sleeper LA, Towbin JA, et al. The incidence of pediatric cardiomyopathy in two regions of the United States. N Engl J Med. 2003;348:1647-1655

2. Nugent AW, Daubeney PE, Chondros P, et al. The epidemiology of childhood cardiomyopathy in Australia. $N$ Engl J Med. 2003;348:1639-1646

3. Lipshultz SE. Ventricular dysfunction clinical research in infants, children and adolescents. Prog Pediatr Cardiol. 2000;12: $1-28$

4. Schwartz ML, Cox GF, Lin AE, et al. Clinical approach to genetic cardiomyopathy in children. Circulation. 1996;94: 2021-2038

5. Towbin JA. Pediatric myocardial disease. Pediatr Clin North Am. 1999;46:289-312

6. Morrow WR. Cardiomyopathy and heart transplantation in children. Curr Opin Cardiol. 2000;15:216-223

7. Kohlschutter A, Hausdorf G. Primary (genetic) cardiomyopathies in infancy: a survey of possible disorders and guidelines for diagnosis. Eur J Pediatr. 1986;145:454-459

8. Rustin P, Lebidois J, Chretien D, et al. Endomyocardial biopsies for early detection of mitochondrial disorders in hypertrophic cardiomyopathies. J Pediatr. 1994;124:224-228

9. Ahdoot J, Galindo A, Alejos JC, et al. Use of OKT3 for acute myocarditis in infants and children. $J$ Heart Lung Transplant. 2000;19:1118-1121

10. Cox GF, Souri M, Aoyama T, et al. Reversal of severe hypertrophic cardiomyopathy and excellent neuropsychologic outcome in very-long-chain acyl-coenzyme A dehydrogenase deficiency. J Pediatr. 1998;133:247-253

11. Helton E, Darragh R, Francis P, et al. Metabolic aspects of myocardial disease and a role for L-carnitine in the treatment of childhood cardiomyopathy. Pediatrics. 2000;105:1260-1270

12. Lee KJ, McCrindle BW, Bohn DJ, et al. Clinical outcomes of acute myocarditis in childhood. Heart. 1999;82:226-233

13. Pierpont ME, Breningstall GN, Stanley CA, Singh A. Familial carnitine transporter defect: a treatable cause of cardiomyopathy in children. Am Heart J. 2000;139:S96-S106

14. Buyse G, Mertens L, Di Salvo G, et al. Idebenone treatment in Friedreich's ataxia: neurological, cardiac, and biochemical monitoring. Neurology. 2003;60:1679-1681

15. Mariotti C, Solari A, Torta D, Marano L, Fiorentini C, Di Donato S. Idebenone treatment in Friedreich patients: oneyear-long randomized placebo-controlled trial. Neurology. 2003;60:1676-1679

16. Grenier MA, Osganian SK, Cox GF, et al. Design and implementation of the North American Pediatric Cardiomyopathy Registry. Am Heart J. 2000;139:S86-S95

17. Richardson P, McKenna W, Bristow M, et al. Report of the 1995 World Health Organization/International Society and
Federation of Cardiology Task Force on the Definition and Classification of Cardiomyopathies. Circulation. 1996;93: 841-842

18. Thiene G, Corrado D, Basso C. Cardiomyopathies: is it time for a molecular classification? Eur Heart J. 2004;25:1772-1775

19. Towbin JA, Lipshultz SE. Genetics of neonatal cardiomyopathy. Curr Opin Cardiol. 1999;14:250-262

20. Akhtar N, Ni J, Stromberg D, Rosenthal GL, Bowles NE, Towbin JA. Tracheal aspirate as a substrate for polymerase chain reaction detection of viral genome in childhood pneumonia and myocarditis. Circulation. 1999;99:2011-2018

21. Bowles NE, Ni J, Marcus F, Towbin JA. The detection of cardiotropic viruses in the myocardium of patients with arrhythmogenic right ventricular dysplasia/cardiomyopathy. J Am Coll Cardiol. 2002;39:892-895

22. Strauss A, Lock JE. Pediatric cardiomyopathy: a long way to go. N Engl J Med. 2003;348:1703-1705

23. Bowles NE, Ni J, Kearney DL, et al. Detection of viruses in myocardial tissues by polymerase chain reaction: evidence of adenovirus as a common cause of myocarditis in children and adults. J Am Coll Cardiol. 2003;42:466-472

24. Bowles NE, Towbin JA. Molecular aspects of myocarditis. Curr Infect Dis Rep. 2000;2:308-314

25. Pauschinger M, Bowles NE, Fuentes-Garcia FJ, et al. Detection of adenoviral genome in the myocardium of adult patients with idiopathic left ventricular dysfunction. Circulation. 1999; 99:1348-1354

26. DeBiasi RL, Edelstein CL, Sherry B, Tyler KL. Calpain inhibition protects against virus-induced apoptotic myocardial injury. J Virol. 2001;75:351-361

27. Bonnet D, de Lonlay P, Gautier I, et al. Efficiency of metabolic screening in childhood cardiomyopathies. Eur Heart J. 1998; 19:790-793

28. Maron BJ, McKenna WJ, Danielson GK, et al. American College of Cardiology/European Society of Cardiology Clinical Expert Consensus Document on Hypertrophic Cardiomyopathy: a report of the American College of Cardiology Foundation Task Force on Clinical Expert Consensus Documents and the European Society of Cardiology Committee for Practice Guidelines. J Am Coll Cardiol. 2003;42:1687-1713

29. Towbin JA, Bowles NE. Genetic abnormalities responsible for dilated cardiomyopathy. Curr Cardiol Rep. 2000;2:475-480

30. Richard P, Charron P, Carrier L, et al. Hypertrophic cardiomyopathy: distribution of disease genes, spectrum of mutations, and implications for a molecular diagnosis strategy. Circulation. 2003;107:2227-2232

31. Maron BJ, Seidman JG, Seidman CE. Proposal for contemporary screening strategies in families with hypertrophic cardiomyopathy. J Am Coll Cardiol. 2004;44:2125-2132 


\section{Factors Associated With Establishing a Causal Diagnosis for Children With Cardiomyopathy}

Gerald F. Cox, Lynn A. Sleeper, April M. Lowe, Jeffrey A. Towbin, Steven D. Colan, E. John Orav, Paul R. Lurie, Jane E. Messere, James D. Wilkinson and Steven E. Lipshultz

Pediatrics 2006;118;1519-1531

DOI: $10.1542 /$ peds.2006-0163

This information is current as of October 4, 2006

$\begin{array}{ll}\begin{array}{l}\text { Updated Information } \\ \text { \& Services }\end{array} & \text { including high-resolution figures, can be found at: } \\ \text { References } & \text { http://www.pediatrics.org/cgi/content/full/118/4/1519 } \\ & \text { This article cites } 31 \text { articles, } 19 \text { of which you can access for free } \\ \text { at: } & \text { http://www.pediatrics.org/cgi/content/full/118/4/1519\#BIBL } \\ \text { Subspecialty Collections } & \text { This article, along with others on similar topics, appears in the } \\ & \text { following collection(s): } \\ & \text { Heart \& Blood Vessels } \\ \text { http://www.pediatrics.org/cgi/collection/heart_and_blood_vessel } & \text { s } \\ & \text { Information about reproducing this article in parts (figures, } \\ \text { tables) or in its entirety can be found online at: } \\ \text { http://www.pediatrics.org/misc/Permissions.shtml } \\ \text { Information about ordering reprints can be found online: } \\ \text { http://www.pediatrics.org/misc/reprints.shtml }\end{array}$

